\title{
Collaborative Learning Aspect for Training Hip and Knee Joint Anatomy
} Nasir Mustafa $^{1^{*}}$, Hina Zahoorand ${ }^{1}$, Fuzail M Majoo ${ }^{1}$ and Azmatullah ${ }^{2}$ Affiliation

${ }^{1}$ Department of Nursing, Istanbul Gelisim University, Turkey

${ }^{2}$ Department of Rheumatology, Istanbul Gelisim University, Turkey

*Corresponding author: Nasir Mustafa, Department of Nursing, Istanbul Gelisim University, Turkey, E mail: nasirmustafaspan@gmail.com

Citation: Mustafa N, Zahoorand H, Majoo MF and Azmatullah. Collaborative learning aspect for training hip and knee joint anatomy (2020) Rheumatic dis treatment J 1: 13-16.

Received: Feb 10, 2020

Accepted: Mar 13, 2020

Published: Mar 20, 2020

Copyright: @ $\odot 2020$ Mustafa N, et al., This is an open-access article distributed under the terms of the Creative Commons Attribution License, which permits unrestricted use, distribution, and reproduction in any medium, provided the original author and source are credited.

\begin{abstract}
One of the prerequisites required for an efficient diagnosis in a medical practice is to have a strong command of both functional and clinical anatomy. In this study we introduce a new collaborative approach in the effective teaching of the knee and hip joint. In the present teaching model, anatomist, orthopedists and physical therapists present the anatomy of the hip and knee joint in small groups. Courses for the hip and knee joint were scheduled during the early stages of the medical curriculum. Students of nursing and physical therapy were grouped together to sensitize for the importance of a collaborative effort. The study results clearly demonstrate that nursing students and physical therapy students appreciated this teaching approach. The collaborative approach further proved to be a suitable method to teach both functional and clinical anatomy of the hip and knee joint. Aside from this training, a collaborative approach between medical students and physical therapy students was also successful for healthcare organization.
\end{abstract}

Keywords: Hip and knee joint anatomy, Collaborative learning, Anatomy teaching, Nursing students, Physiotherapy students.

\section{Introduction}

It is essential for clinicians and physicians to command an excellent understanding of functional anatomy. Surgeons and orthopedists are required to have a cavernous understanding of functional human anatomy and their respective anatomical structures [1]. Cadavers and plastic models are generally used to teach in gross anatomy courses [2]. At Istanbul Gelisim University, human anatomy is taught in preclinical courses to students during the first two semesters as part of their fundamental medical education $[3,4]$. Orthopedic examination courses are assigned at a later time as part of the clinical aspect of the curriculum. While both topics are closely related educationally, they are taught independently of one other [5,6].

Interestingly, several studies have shown that the preservation of anatomical knowledge from the commencement of the medical education to the later clinical phases is meager [1,7]. These observations correlate well with the fact that many advanced students and recent graduates feel insufficiently prepared in anatomy for practical clinical tasks [8]. Furthermore, the extended duration between gross anatomy courses, clinical applications and examinations; the lack of applied and functional instruction of anatomical knowledge from the beginning of the medical education is likely to be a relevant factor [9]. As the modern healthcare system shifts towards interdisciplinary and collaborative approach care, medical education including courses in anatomy should take these developments into consideration by modifying the current curricula [10]. Moreover, a collaborative approach is of outstanding significance for clinical healthcare (Figure 1).

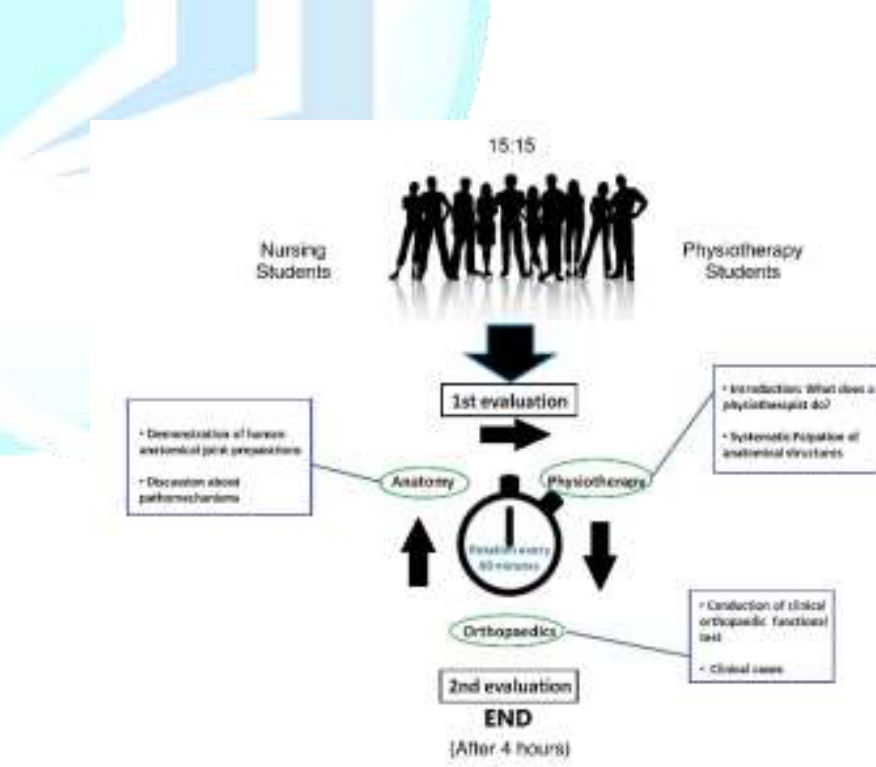

Figure 1: Schematic overview of the collaborative learning aspect course design.

Material and Methods

Citation: Mustafa N, Zahoorand H, Majoo MF and Azmatullah. Collaborative learning aspect for training hip and knee joint anatomy (2020) Rheumatic dis treatment J 1: 13-16. 


\section{Sample}

Every course was designed for 30 students (15 nursing and 15 physiotherapy students) per day. The course enrollment list was made available at the beginning of the anatomic preparation course. As the demand for participation increased, additional students were accepted From 2016 to 2017,230 individuals participated in the course of which 115 were physiotherapy students.

\section{Anatomical Preparations of Hip and Knee Joints}

Body plastic models were used for preparations of hip and knee joint and the respective hip and knee ligaments including menisci. Images were taken using a Nikon D5300 DSLR camera (Mitsubishi Group) and figure panels were designed, processed and labeled using Adobe Illustrator CCgraphic software (Adobe Inc) (Figure 2).

\section{Methodological Instrument}

The evaluation was conducted at the commencement and culmination of every course. Standardized questionnaires were designed using items of the Heidelberger Inventory (HILVE-I/II) [11]. Briefly, multidimensional questionnaires were designed and used for the assessment of teaching quality and teaching by students and teachers and further considered aspects such as motivation and potential benefits for participants.
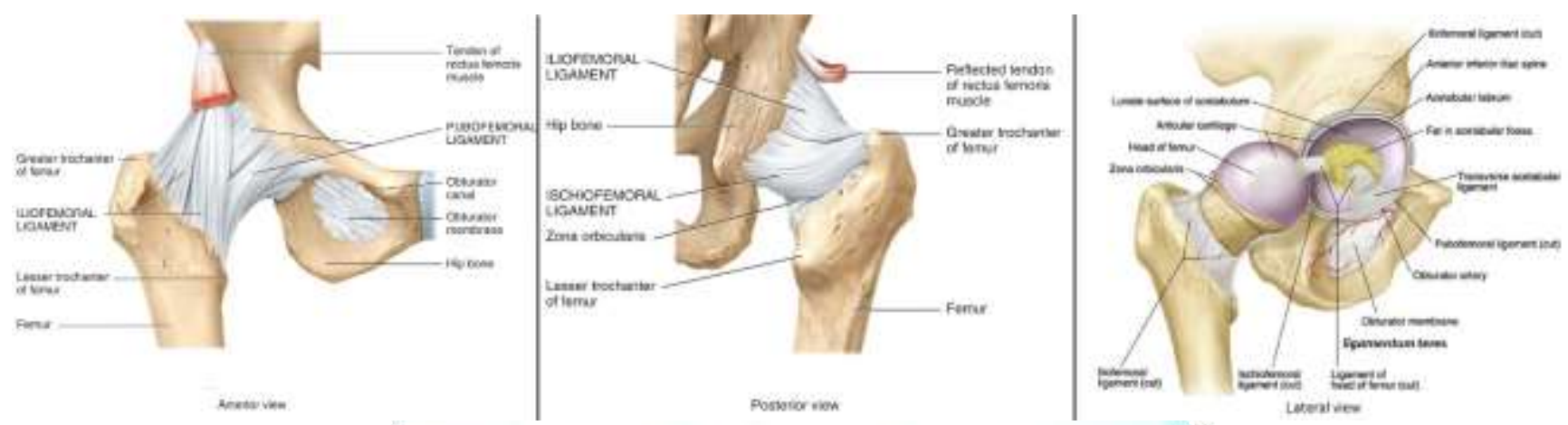

Figure 2: Anatomical hip joint preparations. Examples of hip joint preparation used throughout the course to demonstrate ligaments of the hip under functional aspects. Ventral (A), dorsal (B) and with ligament are depicted (C).

The number of correct answers concerning the "hip and knee" in the anatomical exam of participants $(\mathrm{n}=108)$ was compared with those of non-participants $(\mathrm{n}=207)$. The anatomical exam contained two questions specifically on the anatomy of the "hip and knee". Data analysis programs used were Microsoft Excel (Microsoft Corporation) and SPSS version 24 (IBM Corporation).

\section{Statistics}

Standard Error of the Mean (SEM) is used for data presentation. All diagrams and statistical analyses were generated and performed using GraphPad Prism7 software (GraphPad Software Inc.).

\section{Results}

\section{Design and Schedule for Course}

The basic educational concept of the course was on the idea of bringing lecturers of different medical disciplines together with students to learn from each other. At this stage we would like to emphasize that at the initiation of this course, the evaluation and fundraising was performed by medical students. To discourage students from over loading their curriculum, participation in the course was made as an elective. The course has been designed as following: an interdisciplinary team consisting of a lecturer for anatomy, an orthopedic surgeon and a physical therapist presented different aspects of the hip and knee joint from their contrastive professional perspectives.

The varying perspectives were intended to help students develop a better understanding of the relevant questions concerning hip and knee joint examination and pathogenic mechanisms of traumatic and degenerative processes. Additionally, the supervisors gave the participants different methods of approach to the same anatomical
Structure. For each course, 30 participants (15 nursing students and 15 physical therapy students) were accepted.

\section{Data Analysis}

The motivation of students was assessed for their participation in the elective course by a pre-course questionnaire in a multiple choice format. Participants were able to choose multiple answers. As shown in Figure 3 and 4 physiotherapy students and nursing students specified that the clinical aspect $(74.2 \% \pm 4.8 \%)$ and the topic itself $(71.9 \% \pm$ $5.3 \%$ ) were the most attractive reasons to participate in the hip and knee joint course. More than fifty percent of all course participants were attracted by the interdisciplinary aspects $(56.6 \% \pm 9.3 \%)$. Preparation for the later anatomical exams was interestingly the least motivating aspect $(41.2 \% \pm 12.9 \%)$. Other points in common mentioned were the physical contact with anatomical preparations or special interest in sport injuries.

In the post-course questionnaire, participants were asked to rate different statements concerning the quality and usefulness of the hip and knee joint course (Figure 5). The most relevant results from these post-course evaluations were that participants had a better understanding of the hip and knee joint anatomy and that the general motivation in anatomy had increased after the course. Moreover, palpation and clinical testing enhanced learning in joint anatomy.

According to the evaluations, the interdisciplinary approach subjectively supported the understanding of hip and knee joint anatomy. Conjointly, these evaluations underline that nursing students and physiotherapy students appreciated this interdisciplinary teaching approach for hip and knee joint anatomy. They were also motivated to participate by both the interdisciplinary and the functional and clinical aspects of the course. 

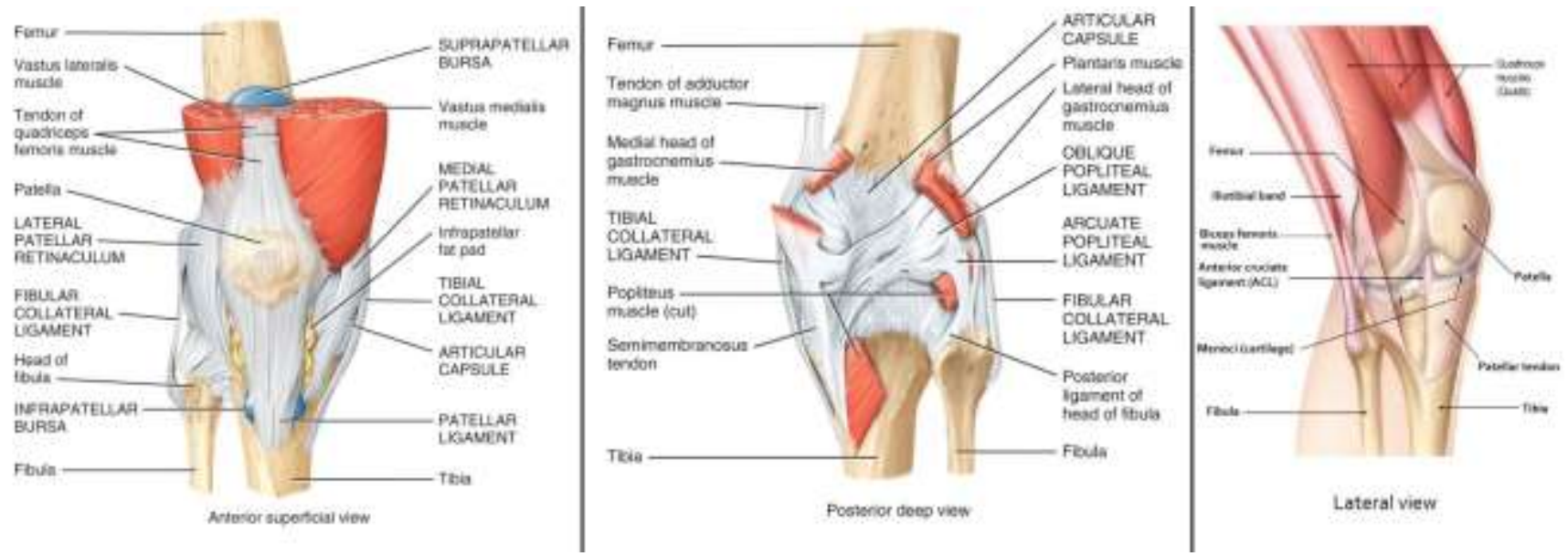

Figure 3: Anatomical knee joint preparations. Examples of knee joint preparation used throughout the course to demonstrate ligaments of the knee under functional aspects. Ventral (A), dorsal (B) and with ligament are depicted (C).

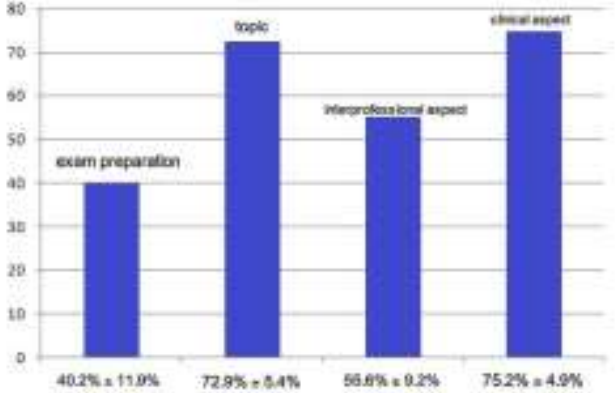

Figure 4: Results of pre-course evaluation for motivation of participants. (A) and post-course evaluations

\section{Analysis of Anatomy Exam Results}

Though Participants thought that the course increased their understanding of hip and knee joint anatomy, we analyzed if students of nursing were better in responding hip and knee joint related questions in the written multiple-choice anatomy exam. To achieve this, we compared the results of hip and knee joint questions of participants and non-participants. As shown in Figure 4 and 5, 74\% of the participants gave corrects answers to the-hip and knee joint related questions, whereas only $65.6 \%$ of the nonparticipants managed to answer correctly. There was no significant difference between the two groups. That said, these preliminary results indicate that-participants are better prepared for the anatomy exams. In order to draw a better conclusion, additional anatomy exams have to be evaluated to ascertain whether participants are better in correctly answering hip and knee joint specific questions.

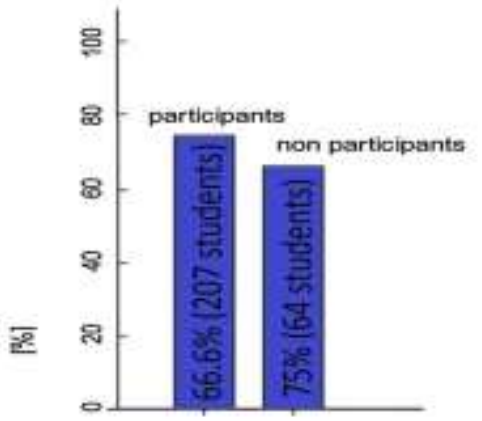

Figure 5: Percentages of correct answers to knee and hip specific multiple choice questions during the written anatomy exam given by participants and non-participants. Differences were not statistically significant.

\section{Discussion}

The presented data in this study show that the interdisciplinary approach to teach hip and knee joint anatomy was well received by both nursing and physiotherapy students. We were able to demonstrate that anatomy of the musculoskeletal system, which is in generally less appreciated and mastered, at least in the case of nursing students becomes much more interesting to learn when connected to questions of clinical relevance. We believe that this teaching approach contributes to a long lasting sensitization for orthopedic questions and a more profound understanding of functional anatomy. Exam results also suggested better performance in answering questions relating to the hip and knee joint of students in the participatory group vs. the nonparticipatory group. It does appear that the evaluation is biased by the fact that it is more likely to have been the more motivated students who would participate in an elective course. However the overall results of participants versus non-participants in the written anatomy exams did not show any significant differences (data not shown), which appears to indicate that this is not the case Figure 6.

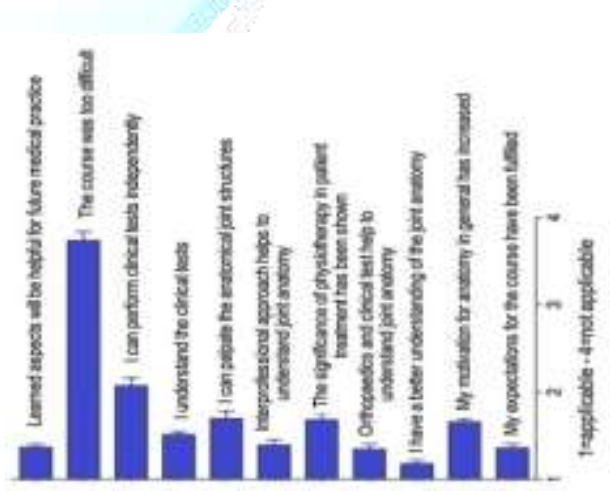

Figure 6: Results of pre-course evaluation for motivation of participants. (B) Multiple answers could be chosen in pre-course evaluations. Data are presented as means \pm SEM from four independent courses.

Given that participation is optional, written anatomical tests to evaluate the benefit of participants due to the course did not seem to be appropriate for evaluation. The effects on anatomical knowledge are difficult to measure as physiotherapist students do not have a written exam at the end of their anatomy studies. In the written anatomy exams 
of the participatory nursing students, initial evaluations of hip and knee specific questions suggested they were superior in correctly answering hip and knee joint specific questions. However, the numbers of questions were too few and more groups have to be analyzed in order to draw more definitive conclusions on the benefit of this teaching approach for later exams. The interdisciplinary approach has been shown to be advantageous for an anatomical teaching concept in different ways. Evaluation results especially from medical students, demonstrate that palpation and clinical tests helped provide a better "feeling" for anatomical structures that are often neglected.

Having students and supervisors of two professions together underlines the importance of healthcare topics. Specifically, second semester nursing students are not aware of the extent to which other health care professionals will cooperate with them at later clinical stages. The World Health Organization WHO (2010, World Health Organization Framework for Action on Inter disciplinary Education \& Collaborative Practice)(WHO/HRH/HPN/10.3), the German Council of Science and Humanities as well as the Advisory Council on the Assessment of Developments in the HealthCare System (Sachver ständigenratzur Begutachtung) Gesundheitsversorgung have stated that interdisciplinary education and research should be extended in order to provide a more integral medical approach in taking advantage of the synergistic effects in bringing together different health care professions [12].

This interdisciplinary course fulfills these requirements and is part of the Longitudinal Strand Interprofessionality (LongStI), which comprises 13 different interdisciplinary projects offered during medical studies. This consortium was created in 2013 by the Nursing Faculty of Istanbul Gelisim University and aims to integrate different interdisciplinary workshops into the medical curriculum. From funds raised in the last three years it has been made possible to acquire additional materials and produce long lasting anatomical preparations. During the next years, courses covering the topics of "shoulder" and the "lumbar vertebral column" will be designed and offered according to the teaching approach presented in this study. With the current resources, continuity is secured for the following years, as additional investments will not be necessary.

\section{Conclusions}

This study presented an interdisciplinary teaching concept for nursing students and physiotherapy students that complement the existing medical curriculum at Istanbul Gelisim University. Evaluation of these courses showed high acceptance and appreciation among participants of both professions. Participation appeared to demonstrate improved anatomy exam results. We propose that this interdisciplinary teaching approach is a contemporary and appropriate method of teaching functional and clinical anatomy, while strengthening interdisciplinary cooperation as an essential aspect of modern healthcare and further fulfilling the requirements for future adaptation of medical teaching and preclinical curricula as requested by the Wissenschaftsrat [13-15]. Upcoming courses will be developed and implemented in the medical curriculum along with improved evaluations, in order to determine the benefit of interdisciplinary teaching in anatomy for anatomy exams and in the future clinical applications.

\section{Acknowledgements}

The authors thank Istanbul Gelisim University faculty and students.

\section{References}

1. Huitt TW, Killins A and Brooks WS. Team-based learning in the gross anatomy laboratory improves academic performance and students' attitudes toward teamwork (2015) Anat Sci Educ 8: 95-103. https://doi.org/10.1002/ase. 1460

2. Older J. Anatomy: A must for teaching the next generation (2004). Surgeon 2: 79-90. https://doi.org/10.1016/S1479-666X(04)80050-7

3. Feigin DS, Magid D, Smirniotopoulos JG and Carbognin SJ. Learning and retaining normal radiographic chest anatomy: does preclinical exposure improve studentperformance? (2007) Acad Radiol 14: 1137-1142.

https://doi.org/10.1016/j.acra.2007.06.023

4. Prince KJAH, Scherpbier AJAA, Van Mameren H, Drukker J and Van Der Vleuten CPM. Do students have sufficient knowledge of clinical anatomy? (2005) Med Educ 39: 326-332.

5. http://dx.doi.org/10.1111/j.1365-2929.2005.02096.x

6. Bohl MA and Gest TR. Resident perceptions of anatomy education: a survey of medical school alumni from two different anatomy curricula and multiple medical specialties (2011) Anat Sci Educ 4: 126-131. https://doi.org/10.1002/ase.207

7. Gogalniceanu P, Palman J, Madani H, Sheena Y, Birch W, et al. Traditional undergraduate anatomy education a contemporary taboo? (2010) ANZ J Surg 80: 6-7. https://doi.org/10.1111/j.1445-2197.2009.05167.x

8. Nieder GL, Parmelee DX, Stolfi A and Hudes PD. Team-based learning in a medical gross anatomy and embryology course (2005) Clin Anat 18: 56-63. https://doi.org/10.1002/ca.20040

9. Wang J, Zhang W, Qin L, Zhao J, Zhang S, et al. Problembased learning in regional anatomy education at Peking University (2010) Anat Sci Educ 3: 121-126. https://doi.org/10.1002/ase.151

10. Shoji H, Solomonow M, Yoshino S, D'Ambrosia R and Dabezies E. Factors affecting postoperative flexion in total knee arthroplasty (1990) Orthopedics 13: 643-649.

11. Kirch DG and Ast C. Interprofessionalism: Educating to meet patient needs (2015) Anat Sci Educ 8: 296-298. https://doi.org/10.1002/ase.1504

12. Rindermann $\mathrm{H}$ and Amelang $\mathrm{M}$. Development and testing of a questionnaire for student event evaluation (1994) Empirical pedagogy 8: 131-151.

13. Walkenhorst $U$ and Schäfer T. Acting together. Doctors and health professionals in training (2012) Med Mabuse 197: 35-37.

14. Leveritt S, McKnight G, Edwards K, Pratten and Merrick D. What anatomy is clinically useful and when should we be teaching it? (2016) Anat Sci Educ 9: 468-475. https://doi.org/10.1002/ase.1596

15. Wissenschaftsrat. Recommendations of the Science Council on the qualification of healthcare personnel (2014). 